\title{
LOS PROBLEMAS PÚBLICOS COMO FACTOR ESTRUCTURAL DE LAS POLÍTICAS PÚBLICAS
} PUBLIC PROBLEMS AS A STRUCTURAL FACTOR OF PUBLIC POLICIES

ANTONIO YESID PEDROZA ESTRADA

Universidad Popular del Cesar, UPC

Escuela Superior de Administración Pública, ESAP

COLOMBIA
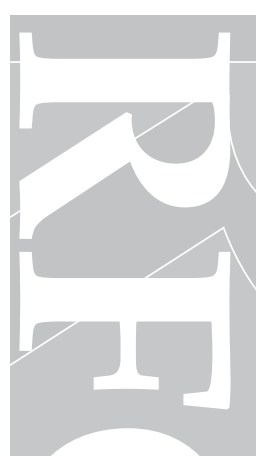

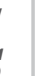

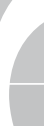




\title{
RESUMEN
}

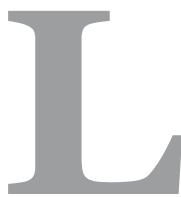

as políticas públicas son, en un gobierno organizado y planificado, las principales estrategias para enfrentar las problemáticas de la comunidad en la búsqueda de soluciones efectivas. Para formular e implementar una política pública debe existir previamente, una razón, un motivo que instigue u obligue a las autoridades públicas a actuar, por razones políticas, sociales o económicas; a esta motivación primaria se le denomina problemas públicos. Esta investigación se desarrolla dentro del paradigma cualitativo, enmarcado dentro de los estudios documentales, utilizando como técnica la hermenéutica, realizando análisis de diferentes vertientes de opinión sobre las políticas públicas, la construcción de los problemas públicos y su relación. La investigación presenta una propuesta, donde la comunidad puede incidir y decidir sobre las problemáticas públicas y por lo tanto en las políticas públicas, por lo que también es investigación proyectiva. Se sustenta en autores como Meny y Thoenig (1992), Cobb y Elder (1993) y Roth (2013). Se plantea un nuevo modelo de políticas públicas a partir de la construcción de problemas públicos como construcción política, mediante mecanismos jurídicos, políticos y comunicacionales, liderados por líderes sociales, para permear la agenda gubernamental.

Palabras clave: políticas públicas, problemas públicos, agenda pública, mecanismo de participación.

\begin{abstract}
Public policies are, in an organized and planned government, the main strategies to face the problems of the community in the search for effective solutions. In order to formulate and implement a public policy, there must previously exist a reason, a reason that instigates or compels public authorities to act, for political, social or economic reasons. This primary motivation is called public problems. This research is developed within the qualitative paradigm, framed within the documentary studies, using hermeneutics as a technique, carrying out analysis of different opinions on public policies, the construction of public problems and their relationship. The research presents a proposal, where the community can influence and decide on public issues and therefore in public policies, so it is also projective research. It is based on authors such as Meny and Thoenig (1992), Cobb and Elder (1993) and Roth (2013). A new model of public policies is proposed from the construction of public problems such as political construction, through legal, political and communication mechanisms, led by social leaders, to permeate the government's agenda.
\end{abstract}

Keywords: public policies, public problems, public agenda, participation mechanism. 


\section{INTRODUCCIÓN}

Las políticas públicas son, en un gobierno organizado y planificado, las principales estrategias para enfrentar las problemáticas de la comunidad en la búsqueda de soluciones efectivas. Pero, para formular e implementar una política pública debe existir, previamente, una razón, un motivo que instigue u obligue a las autoridades públicas a actuar; es decir, un interés inicial por un problema social que atraiga o le convenga al gobernante o a la comunidad. A este proceso de construcción política se le denomina: construcción de problemas públicos.

Los problemas públicos, son, desde la perspectiva de Meny y Thoenig (1992) construcciones políticas de una colectividad o una comunidad, en un espacio y tiempo determinado, mediante el cual logran que un problema social se incluya en la agenda de gobierno. Mientras que las políticas públicas se vislumbran como la actuación de una autoridad pública frente a un problema público.

Se plantea una mirada rápida sobre la conceptualización de las políticas públicas y una propuesta sobre la construcción de problemas públicos a partir de problemas sociales teniendo como protagonistas los líderes comunitarios, con el claro propósito de proponer un ejercicio eficaz de poder participativo por parte de la comunidad en un Estado social de derecho, a partir de crear mecanismos jurídico - políticos que formen y apoyen la ciudadanía con el objetivo de permear la agenda de los gobernantes con la consecuencia lógica de crear e implementar políticas públicas más cerca de la voluntad de la misma.

\section{METODOLOGíA}

El paradigma utilizado en esta investigación es de enfoque cualitativo e interpretativo, ya que la investigación es guiada, por lo que algunos autores llaman un diseño emergente, en contraposición a un diseño previo (Briones, 2003). No se presenta hipótesis, por lo que encuadra en lo expuesto por Hernández y otros (2016) para quienes en la mayoría de los estudios cualitativos no se prueban hipótesis, estas se generan durante el proceso y van refinándose conforme se recaban más datos.

En consecuencia, se pretende con este trabajo estudiar una realidad sin modificarla; en palabras de Rodríguez, Gil y García (2011) la investigación cualitativa estudia la realidad en su contexto natural, tal y como sucede, intentando sacar sentido de, o interpretar, los fenómenos de acuerdo con los significados que tiene en los sujetos implicados.

Éste estudio, además, se enmarca dentro de los estudios documentales, utilizando como técnica el análisis documental, siguiendo a Hernández y otros (2016) el que consideran di- 


\begin{tabular}{c}
\hline ANTONIO YESID PEDROZA ESTRADA \\
$>126$ LOS PROBLEMAS PÚBLICOS COMO FACTOR ESTRUCTURAL DE LAS POLÍTICAS PÚBLICAS \\
Págs. $123-143$. DOI: $h t t p: / / d x . d o i . o r g / 10.30972 / r f c e .0203258$
\end{tabular}

ferentes vertientes académicas sobre las políticas públicas, la construcción de los problemas públicos y su relación con las mismas. Por otro lado, se presenta una nueva propuesta para que la comunidad incida en la formación de la agenda gubernamental con la inclusión de las problemáticas que más le interesan o necesitan; por lo que se enmarca también dentro de la investigación proyectiva, (Hurtado, 2010, p.565).

\section{CONTEXTUALIZACIÓN}

\subsection{LAS POLÍTICAS PÚBLICAS}

Lograr que se establezca una paz estable y duradera en Colombia exige cambios estructurales y para eso uno de los puntos fundamentales en los acuerdos políticos, firmados en la Habana entre el Estado colombiano y la antigua guerrilla de las FARC, es fortalecer los mecanismos de participación ciudadana; transformándolos de meros instrumentos simbólicos a herramientas eficaces que le atribuyan al ciudadano poder de influir y definir en su desarrollo y futuro.

El desafío es fundar un verdadero proyecto de nación, un ideario colectivo con una clase hegemónica determinada a conseguir un desarrollo económico que coloque a Colombia en el camino de las grandes economías globales. Los problemas públicos como construcción política por parte de la comunidad son el elemento básico para la construcción de políticas públicas que enfrenten las diferentes problemáticas sociales.

Un país referente para desarrollarnos son los Estados Unidos de Norte América. Fukuyama et al. (2006) tratando de explicar la brecha, en el desarrollo, entre América Latina y Estados Unidos, propone tres categorías de factores que han podido influir en la diferencia:1) las políticas públicas; 2) Las instituciones políticas destinadas a mitigar conflictos sociales y promover acciones colectivas; y 3 ) la estructura social refiriéndose a divisiones de clanes, razas y regiones, entre otras. La propuesta inscrita en este trabajo consiste en proponer la Construcción de Problemas Públicos como estrategia para crear nuevas instituciones públicas para influir en la construcción de políticas públicas, por lo que entraría a subsanar las falencias en dos de los puntos enumerados por el autor citado.

Entre las instituciones sociales que califica Fukuyama et al (2006) como falibles se encuentran las llamadas, instituciones macropolíticas, la forma como ejerce la autoridad el poder ejecutivo, así como también las normas y los hábitos informales, que influyen en la manera de actuar de las instituciones formales. En estos dos aspectos, también, encaja la propuesta de esta investigación, primero, porque propone crear instituciones macropolíticas que le permitan al ciudadano ejercer mecanismos de presión legales y legitimos que le ayuden a modificar la agenda del gobernante imponiendo sus intereses o negociando 
parte de ellos; es decir, la construcción de problemas públicos. Y por otro lado, se propone fortalecer la creación de nuevas instituciones que trabajen en la construcción de cambios culturales, así como la implementación de estrategias legales, racionales y altamente democráticas que intervengan en las acciones y políticas públicas de los gobernantes en el orden nacional y territorial.

Respecto a la definición de política pública diversos autores, de dos grandes escuelas: la anglosajona y la francesa, proponen distintos objetivos, características, así como formas de implementarla o de evaluarla. Entre algunas definiciones tenemos:

a) Para Ruiz y Cadena (s.f.) "Las Políticas Públicas son las acciones de gobierno, es la acción emitida por éste, que busca cómo dar respuestas a las diversas demandas de la sociedad".

b) El docente e investigador Roth (2013) considera que una política pública:

(...) designa la existencia de un conjunto conformado por uno o varios objetivos colectivos considerados necesarios o deseables y por medios y acciones que son tratados, por lo menos parcialmente, por una institución u organización gubernamental con la finalidad de orientar el comportamiento de actores individuales o colectivos para modificar una situación percibida como insatisfactoria o problemática (p. 27).

c) Según Meny y Thoenig (1992, p.89) una política pública es: "el resultado de la actividad de una autoridad investida de poder público y de legitimidad gubernamental". Más adelante, los autores citados añaden: "Una política pública se presenta como un programa de acción gubernamental en un sector de la sociedad o en un espacio geográfico: la seguridad, la salud, los trabajadores inmigrantes, la ciudad de Paris, la Comunidad Europea, el Océano Pacífico, etc.”.

Pero también, una política pública es la acción o actuación programada o planificada de una autoridad pública frente a un problema público; entendiendo un problema público como una construcción política colectiva de una comunidad determinada respecto de una carencia objetiva; es decir, un problema social que le interesa sea resuelto. Como corolario de lo anterior, una acción gubernamental se constituirá como política pública sólo si se realiza frente a un problema público, por lo que el mismo se instituye como factor estructural de las mismas.

\subsubsection{CARACTERÍSTICAS DE UNA POLÍTICA PÚBLICA}

Para diferenciar una política pública de otras acciones de los gobernantes como, por ejemplo, los meros actos de gobierno, no planificados y coyunturales por causas que pueden ser intereses politiqueros, corrupción o meramente publicitarios, las políticas públi- 
cas, para que puedan ser identificadas, analizadas y evaluadas, tienen características definidas, ya sea para medir su impacto, eficiencia, eficacia que la muestren como exitosa, o por el contrario, expresen errores por los que se decide modificarlas o terminarlas para no seguir ejecutándolas.

Diversos autores las enuncian, tal es el caso de Meny y Thoenig (1992) quienes disponen que una política pública se distingue por tener. a) Un contenido que se va a ver reflejado en los productos de la actuación gubernamental, b) un programa en el que puede distinguirse una coherencia articulada entre diferentes acciones y actuaciones de gobierno que permiten identificar un denominador común, c) una orientación normativa que permite visibilizar la expresión de las preferencias del decisor, sus valores, sus intereses o la de los que dominan la agenda pública, d) un factor de coerción que le permite a la autoridad pública imponer, si es caso, sus decisiones a través del monopolio de la fuerza legítima, facultad que no la puede ejercer un ente privado, y finalmente, e) una competencia social que compete a los actos y disposiciones que afectan la situación que se enfrenta: es decir, el problema público, así como el comportamiento de la comunidad administrada y afectada por la acción pública. Una política pública es el instrumento de una ideología o proyecto político, sus acciones se proponen captar o perpetuarse en el poder.

\subsection{LOS PROBLEMAS PÚBLICOS}

Reforzar la sociedad civil, en las democracias, implica necesariamente darle la posibilidad a la ciudadanía de influir eficazmente en la solución de los problemas sociales usando sus recursos, pero también y ante todo, pudiendo ser decisorio cuando se direccionen los recursos estatales en dirección de sus intereses en forma de políticas públicas, ese es el reto de los gobernantes actuales y futuros, pero sobre todo debe ser un propósito del Estado. Al respecto Soros (2002) expresa que:

"La democracia y la apertura de la sociedad no puede ser impuesta desde el exterior porque el principio de la soberanía no permite las injerencias. Una estrategia posible sería reforzar la sociedad civil y ofrecer incentivos a los gobiernos que pongan en marcha reformas económicas y políticas" (p.40).

El pueblo colombiano está deseoso de cambiar las condiciones que ha venido padeciendo en los últimos sesenta años, sobre todo en el tema de la confrontación armada; pero la mayoría de la ciudadanía es conciente que para que se produzca un verdadero cambio estructural que construya los cimientos de una paz duradera se tienen que cambiar las condiciones sociales y económicas de la mayoría de sus habitantes; uno de los pilares de una nueva sociedad bajo un modelo innovador por el gobierno sería desarrollar estrategias que permitan el fortalecimiento de la capacidad de influir por parte de los líderes comunitarios en la construcción de problemas públicos como factor básico en las políticas públicas. 


\subsection{CONTEXTO POLÍTICO DE LOS PROBLEMAS PÚBLICOS}

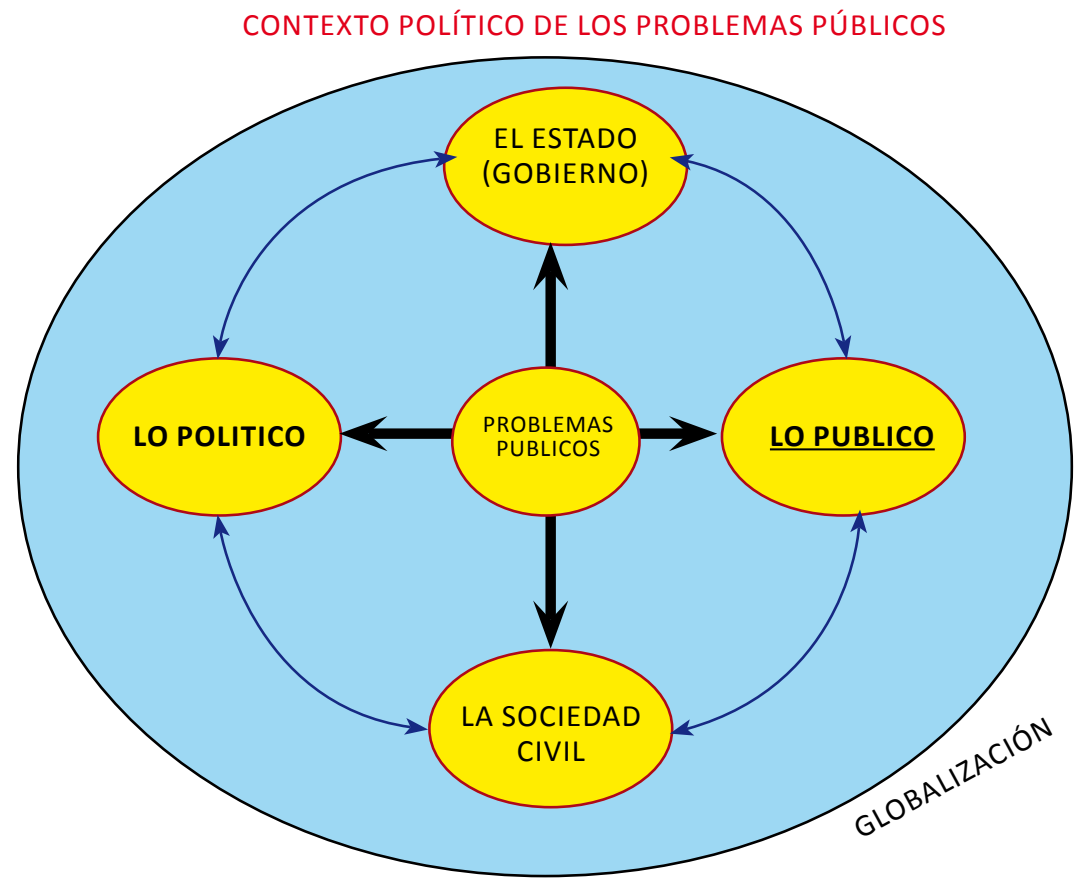

MODELO EN CONSTRUCCIÓN PROPUESTO POR: ANTONIO YESID PEDROZA ESTRADA

Fuente: elaboración propia.

\subsubsection{LA GLOBALIZACIÓN}

La globalización para muchos no es más que un fenómeno económico. Soros (2002) equipara globalización con el desarrollo de mercados financieros globales y el crecimiento de corporaciones transnacionales con su creciente dominio sobre las economías globales; restándole importancia al debate acerca de la globalización de la información y la cultura, de la expansión de la televisión, Internet y otras formas de comunicación o de la pujante movilidad y comercialización de ideas. El debate acerca de cuál es primero, si el cambio cultural o el cambio del modelo económico, no es transcendental en este momento, pero es incuestionable que las tecnologías de la comunicación y de la información construyen cada día un nuevo ciudadano global, enterado e interesado en los problemas de la sociedad global y con un ejercicio permanente de comparación entre la realidad que lo circunda y lo que ve en otros pueblos. Este cotejo continúo permea los elementos que construyen los problemas públicos.

\subsubsection{EL ESTADO}

El Estado, como forma de organización política para un territorio, hoy es confrontado con mayor ahínco y conocimiento; es retado por la ciudadanía a cumplir con sus obliga- 
ciones aminorando los espacios de poder de la clase hegemónica y sus gobernantes, la mayoría pertenecientes a grupos políticos entronizados en el poder local, con burocracias propias que le funcionan como máquinas para seguir enclavados en su manejo, se ven amenazados por nuevos liderazgos sin abolengo o estructuras políticas fomentados por nuevas formas de comunicación con el ciudadano elector; las redes de información a través de computadores y teléfonos digitales, son los nuevos caballos de Troya que permiten cabalgar en un espacio infinito virtual. En este universo virtual no existen barreras, a manera de un lugar donde se podría hacer posible la construcción de un nuevo ser humano global sin distinciones de cualquier índole. Este es el ciudadano que enfrentan hoy el Estado y los gobiernos, culturizado tecnológicamente, cada día más interesado en hacer control social a los gobiernos.

\section{3•3•3. LO PÚBLICO}

Por los mismos cambios tecnológicos la dicotomía de lo público y lo privado cada vez se deforma más. Esa diferencia parece ser más difusa cada día; las nuevas formas de comunicación hacen difícil distinguir los tradicionales conceptos de lo público, lo privado e incluso lo íntimo. Pero también pareciera que se expande más la idea de una comunicación instantánea, general, donde podría conocerse la opinión de la colectividad en una especie de ágora virtual; la comunicación no es el problema, el desafío es confiar en que esa opinión, emitida a través de cualquier medio, además de ser cierta, cuenta con formación política y libertad crítica.

La construcción de lo público como producto del cotejo de ideas e intereses es más fácil hoy por efecto de los mecanismos comunicativos técnicos, sea cual fuere su fondo, se puede tener más confianza en lo que se conoce, en un escenario ideal, como opinión de la ciudadanía; por lo que los gobiernos deben trabajar más en el diseño de nuevos mecanismos de participación buscando transparencia y menos corrupción e ir haciéndose a la idea que los manejos de los recursos son más vigilados por un ciudadano más formado e informado.

\subsubsection{LA SOCIEDAD CIVIL}

El Banco Mundial (2016) difunde en su página web que, la sociedad civil juega un papel decisivo en dar a conocer las opiniones de los pobres con respecto a las decisiones que afectan sus vidas; para esta institución financiera de tipo global, la sociedad civil está compuesta, según el Banco mundial (2016) por organizaciones no gubernamentales, grupos basados en su fe común, sindicatos, poblaciones indígenas y originarias, organizaciones de caridad, agrupaciones locales y fundaciones privadas, que se han transformado en una fuerza importante en el desarrollo internacional durante los últimos 20 años. Está sociedad civil está conformada 
por el sector social que no hace parte de la estructura estatal, pero que se organiza para actuar frente a los problemas de la comunidad.

El Banco Mundial (2016) reporta que se ha producido un drástico aumento en el tamaño, esfera de acción y capacidad de la sociedad civil en el mundo, ayudado, según ellos, por la mayor gobernabilidad democrática y la globalización. Como ejemplo, se informó que el número de ONG internacionales aumentó de 6.000 en 1990 a 26.000 en 1999. Las Organizaciones de la Sociedad Civil también se han convertido en importantes actores en lo referente a la ayuda mundial; la Organización de Cooperación y Desarrollo Económicos (OCDE) informa que, a finales de los años 1990, estas organizaciones aportaban anualmente unos US\$ 6.000 millones a US\$ 7.00o millones de sus propios recursos.

Asevera el Banco Mundial que la influencia y habilidad de las Organizaciones de la Sociedad Civil en la formulación de las políticas públicas mundiales también ha crecido durante las dos últimas décadas. Este dinamismo se refleja en las exitosas campañas de promoción de diferentes causas, como la prohibición de las minas terrestres, la cancelación de deudas y la protección ambiental, que han movilizado a miles de simpatizantes en todo el mundo.

Para el Banco Mundial la sociedad civil, las asociaciones entre la sociedad civil, el gobierno y el sector privado se han convertido en la manera más afectiva de lograr el crecimiento económico y el desarrollo social sostenible, por lo que existen beneficios al establecerse una mayor participación por las partes interesadas ya que al quedar representada por las Organizaciones de la Sociedad Civil, la gente pobre y marginada puede lograr que sus opiniones se tomen en cuenta al momento de decidir las políticas y los programas.

La política tiene entre sus propósitos ejercer el poder para buscar resolver, minimizar o enfrentar los diversos intereses que producen en una comunidad determinada. El ambiente de creación de la política es la confrontación racional, con ideas y argumentos. Pero este ambiente no es estable depende de muchas variables: el tiempo, el espacio como expresión del territorio, fenómenos climáticos y geográficos, cambios tecnológicos, modelos económicos, eventos catastróficos, etc. En Colombia la política es muy dinámica, sobre todo en los últimos años, en los que se viene realizando todo un proceso para consolidar la terminación del conflicto armado con una de las guerrillas más antiguas del mundo. Lograr que se establezca una paz estable y duradera exige cambios estructurales y para eso uno de los puntos fundamentales en los acuerdos políticos es fortalecer los mecanismos de participación ciudadana; transformándolos de meros instrumentos simbólicos a herramientas eficaces que le atribuyan al ciudadano poder de influir y definir en su desarrollo y futuro. Hay que ir cerrando la brecha económica, educativa, política y cultural entre los colombianos; el desafío es fundar un verdadero proyecto de nación, un ideario colectivo con una clase hegemónica determinada a conseguir un desarrollo económico que coloque a Colombia en el camino de grandes economías globales. 


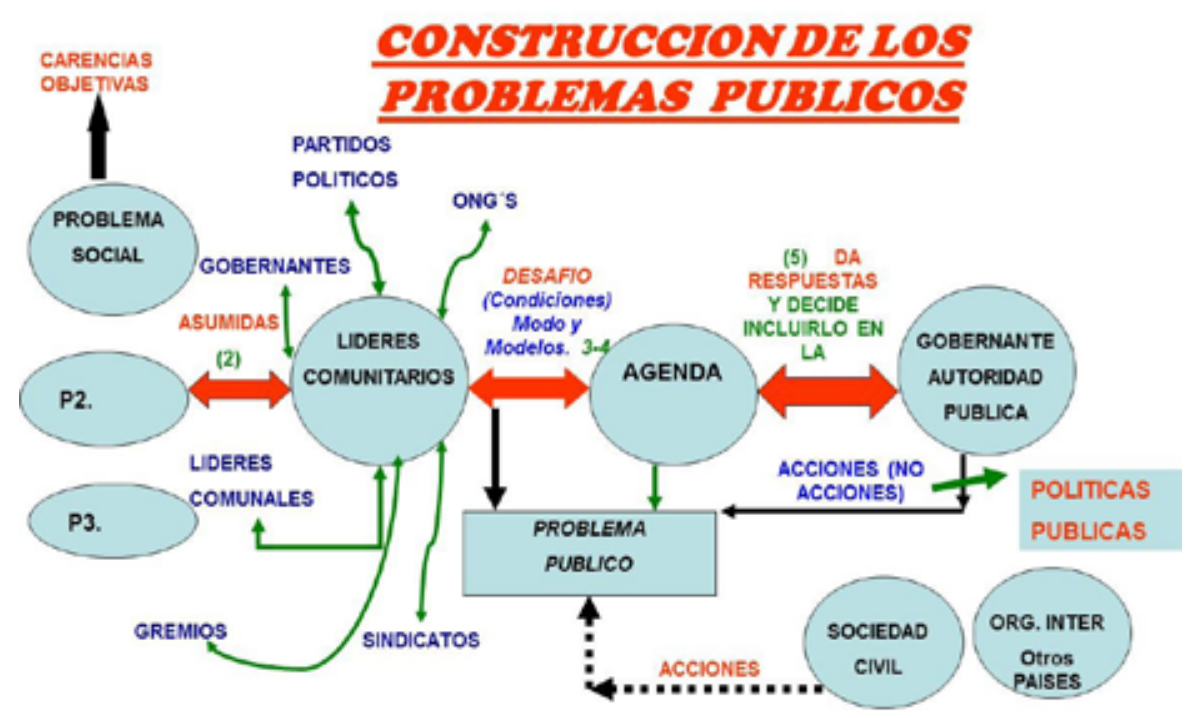

Figura 1. Modelo en construcción propuesto por Antonio Yesid Estrada

Fuente: Antonio Y. Pedroza (2016)

Para convertir un problema social en un problema público debe crearse un contexto democrático en donde se empodere a los líderes comunitarios con la construcción de nuevos instrumentos jurídico-políticos que le permitan influenciar la agenda gubernamental. Siguiendo la figura 1 se expone el modelo propuesto:

\section{a) El problema social}

La sociedad tiene problemáticas y las tendrá muy seguramente hasta que el hombre exista. El ser humano es dialéctico e inacabado por lo que nunca estará satisfecho completamente. Maslow (2005) plantea en su teoría sobre la motivación humana, una escala de necesidades que movilizan a las personas o sea que las impulsa en un sentido u otro. Propone cinco categorías de necesidades que poseen un orden escalonado ascendente de acuerdo a su importancia para la supervivencia y la capacidad de motivación; es decir, en la medida que el ser humano satisface una necesidad, en forma razonable o satisfactoria, surgen otras que cambian o modifican el comportamiento del mismo; proyectando una nueva necesidad.

Las cinco categorías de necesidades son: fisiológicas, de seguridad, de amor y pertenencia, de estima y de ser o auto-realización; siendo las necesidades fisiológicas las de más bajo nivel y las de auto realización las más complicadas ya que dependen mucho de la subjetividad de cada individuo.

En cualquier comunidad la multiplicidad de penurias y privaciones es una constante, afectando los múltiples factores pertenecientes a las escalas que definió Maslow (2005), las 
particularidades dependerán de factores internos y externos de las personas y del medio dependiendo de infinidad de variables. Estas carencias o necesidades son objetivas, es decir, existen por construcción de los individuos que conforman una comunidad particular.

Una problemática es colectiva, cuando afecta a más de un sujeto en forma tal que crea una especie de solidaridad o causa común. El interés público o social no es más que la sumatoria de los intereses particulares. El peso de cada uno de los problemas obedecerá ya sea al número de afectados por la situación problémica, a la calidad de las personas, a los intereses económicos o políticos en juego, o a cualquier otra circunstancia que implique un juego de poder. En la mayoría de los casos es consecuencia del tipo de interés que tenga el empresario político que decide asumirlo.

Becker (como se citó en Meny y Thoenig, 1992) expone en su análisis de los problemas sociales que la existencia de éstos puede proceder de varias fuentes posibles: primero, a las carencias objetivas de una sociedad. Un problema social está determinado por insatisfacciones de las personas y el juicio de valores acerca de la importancia de las mismas. Y segundo, un problema social puede surgir, también, de una confrontación de visiones, ideologías, o intereses disimiles entre miembros de una comunidad.

Sin embargo, no todos los problemas de la sociedad, sea cual fuere su origen, pueden ser solucionados o enfrentados por las autoridades públicas debido a que los recursos con los que se cuenta son limitados e insuficientes. Existe, entonces, una competencia por parte de las diferentes comunidades con sus problemáticas frente a la autoridad pública para que ésta enfrente su causa en busca de solución o por lo menos de atención.

Para Aguilar et al (1993) los problemas y las situaciones problemáticas son diferentes, mientras que:

Las "situaciones problemáticas" son efectivamente hechos vividos u observados por el sujeto y que al ser referidos a su cuadro valorativo arrojan conclusiones negativas de reprobación y malestar. Se trata de discrepancias entre las condiciones vividas u observadas y las deseadas, entre lo que efectivamente ocurre y lo que se desea ocurriera, entre el ser y el deber ser. La vida en sociedad está llena de estos problemas vitales o situaciones problemáticas. Los individuos y los grupos en su interacción experimentan necesidades, problemas, conflictos, en el momento en que sus experiencias chocan con sus preferencias, no importa cómo éstas se hayan formado en su personalidad o en sus organizaciones, si sean ordenadas o fantasiosas (p.58).

Los problemas, por otro lado, tienen una naturaleza cognoscitiva más que vital o valorativa, son construcciones lógicas, que articulan, ordenan, los datos, así como elementos que son reunidos en una definición. Así, un problema social debe ser planteado ante una autoridad pública de forma tal que contengan unas razones, alguna información, sujetos 
interesados y sobre todo deben vislumbrarse posibles soluciones de manera tal que una autoridad pública pueda actuar, o no, consecuentemente con los recursos legales, presupuestales, fiscales, políticos y administrativos que disponga. Cuando la autoridad pública resuelve enfrentar el problema social, justo en este momento se convierte un problema social en un problema público que debe ser enfrentado con una política pública. Esta es la clave del modelo que presentamos aquí.

Formular una nueva forma de valorar la construcción de problemas públicos por el ciudadano, líder comunitario, que tenga efectividad en la búsqueda de la satisfacción de sus intereses mediante la implementación de políticas públicas, es el objetivo central de esta propuesta. Se pretende proponer nuevos instrumentos jurídico - políticos que puedan realizar los líderes comunitarios para que puedan transformar los problemas sociales en problemas públicos, bajo la premisa que todos los problemas de la comunidad son problemas sociales pero no todos son problemas públicos, motivado en que los segundos son construcciones políticas que obedecen a una dinámica de poder compleja que puede aprehenderse mediante un proceso de formación y apoyo por las instituciones estatales, con un objetivo final: presionar la implementación de políticas públicas con relación a los intereses de los mismos.

\section{b) Los líderes comunitarios como empresarios políticos}

Un gobernante frente a la infinidad de problemas sociales tiene muchas limitaciones. Estas restricciones son económicas principalmente y se reflejan en su presupuesto, por lo que éste debe ser priorizado siguiendo el camino de los intereses de quien decide o de quienes llevan al decisor a actuar en la dirección que ellos deseen.

Otros tipos de condiciones que someten el desempeño del gobernante frente a las contrariedades sociales, suelen ser de tipo legal, cultural, religioso o político en general. El Gobernante no toma sus decisiones en forma aislada, los intereses de los demás actores inmersos en la dinámica de poder también cuentan. El líder comunitario para convertir problemas sociales en problemas públicos debe trazar estrategias que obliguen o motiven al gobernante a incluir los intereses que él lidera en la agenda de gobierno.

El líder comunitario primeramente, para propugnar por la transformación de un problema social en problema público, debe asumir como suyo el descontento o inconformidad que tenga la comunidad o una parte de ella.

Segundo, el líder comunitario debe tener conocimientos que le faciliten identificar un problema social; cuál es la esencia del mismo, quienes son los interesados y los afectados en diferentes niveles, cuáles son las principales causas y consecuencias de éste, así como también definir si en principio la solución a la problemática puede ser enfrentada por la sociedad civil.

Tercero, un líder comunitario debe tener una caja de herramientas con instrumentos de tipo psicológico, político y sociológico que le facilite la tarea de influenciar a su comunidad, es 
decir, es preponderante la autoformación y la capacitación constante, el líder estudia constantemente con respecto a la tarea de alinderar intereses.

Para que se fortalezca lo propuesto anteriormente como política pública de fortalecimiento de la democracia participativa, el Estado debe consolidar estrategias a través de sus autoridades públicas nacionales y territoriales para identificar los líderes naturales de una comunidad o aquellos ciudadanos que poseen las cualidades y calidades morales, éticas y ciudadanas que pudieran serlo, en una labor constante no aislada o eventual.

Luego, sensibilizarlos y motivarlos a que se formen en competencias organizativas que le ayuden a identificar y priorizar problemas sociales. El Estado debe asumir políticas públicas encaminadas a la construcción de una red interna de líderes comunitarios que le ayuden en primera línea, como aliados, a reconocer el foco de las inconformidades sociales y su posible auto solución en un ejercicio de libertad de conciencia sin ningún tipo de alineación o pretensión diferente al interés general.

Un paso importante en este proceso, es educar y formar al líder comunitario en teorías sobre políticas públicas e instrumentos de participación y control ciudadano que le faciliten la tarea de usarlos con el objetivo de instigar a una autoridad pública a tomar en cuenta sus peticiones transformándolas en especie de nuevo desafío al que no le puede rehuir. Se trata como fin último de la formación o transformación por parte de las instituciones estatales en convertir al líder comunitario en empresario político de cambio social.

Respecto al papel del líder como empresario político, Meny y Thoenig (1992) los dividen en dos tipos: el primero, los que se identifican fácilmente por ser parte de un gremio o grupo que ejerce en forma profesional y reúne grupos, medios o individuos que integran elites sociales, culturales, económicas o políticas. El segundo tipo de empresarios políticos se encuentra en el seno de conjuntos más difusos, anónimos y que puede aparecer esporádicamente y desaparecer posteriormente.

A veces la desventaja estratégica que tienen los segundos de los primeros es la falta de notoriedad, de influencia o de contactos con las autoridades públicas, que son reemplazadas por el activismo, la radicalización y el número de ciudadanos interesados que lo respaldan pudiendo a constituir asociaciones especializadas.

Para identificar cuales ciudadanos están interesados en una problemática social determinada, el líder comunitario debe tener claro que frente a la misma cada individuo tiene una visión particular producto de su interés. Cobb y Elder (1993) exponen que dependiendo de la capacidad para implementar estrategias de movilización social que permitan ejercer mayor presión a las autoridades públicas, en un conflicto se podrían distinguir dos grandes grupos: i) los actores propiamente dichos, es decir, los que ejercen profesionalmente como empresarios políticos, y por lo tanto tienen a su disposición instituciones sociales como ONG, partidos políticos, medios de comunicación masivos, aquellos que desarrollen mayor actividad se les 


\begin{tabular}{c}
\hline ANTONIO YESID PEDROZA ESTRADA \\
$>136$ LOS PROBLEMAS PÚBLICOS COMO FACTOR ESTRUCTURAL DE LAS POLÍTICAS PÚBLICAS \\
Págs. $123-143$. DOI: $h t t p: / / d x . d o i . o r g / 10.30972 / r f c e .0203258$
\end{tabular}

denominan grupos de identificación, mientras que los de menor dinamismo se erigen como grupos de atención con relación al problema. ii) Los públicos, son los ciudadanos que no son tocados directamente por el problema social.

Aquellos ciudadanos que por iniciativa propia o por acciones de los empresarios políticos se informan o se implican en el desarrollo del conflicto, se les conoce como públicos interesados; mientras que, los ciudadanos que se mantienen más alejados componen el público en general.

La labor del líder comunitario es trabajar para mantener la mayor cantidad de público interesado en lo que propone como problema social. Para hacerlo el líder comunitario, según Cobb y Elder (1993), como empresario político, debe reflexionar acerca de sus intereses respecto a la problemática elegida para trabajar, es decir, si él está siendo afectado. Si es así puede tener varias dificultades tales como: a) puede perder legitimidad frente a la autoridad competente y con el resto de la comunidad que no es afectada directamente pero que en un momento determinado podría apoyar el reclamo; b) en el debate para buscar soluciones podrían existir sesgos involuntarios o intencionados por el líder comunitario por sentimientos o prejuicios que él tenga, demorando las acciones de las autoridades públicas en el tratamiento de la problemática social; c) el gobernante u otros actores comunitarios interesados en que sea otro problema el que tenga más relevancia social pueden presentar la situación como un dilema ético desacreditando al líder comunitario y por lo tanto perjudicando a toda la comunidad que necesita que sus necesidades sean atendidas.

En caso de no tener intereses directos, para el líder comunitario el margen de maniobra es mayor en cuanto a que los reclamos presentados ante la sociedad pueden tener más legitimidad. El líder comunitario debe tratar de mantener, en lo posible, una posición lo más impersonal posible sobre el tratamiento y soluciones de la problemática, pues, una acción por las autoridades públicas respecto al problema que él lidera puede ser el inicio de futuros éxitos.

Por otro lado, el líder comunitario que quiera ir aumentando su capital de influencia y de poder con respecto a la comunidad tiene que estar atento, oteando el horizonte como un cazador, ponderando cuál de los diferentes descontentos que afectan a la comunidad puede ser asumida con el mayor porcentaje de éxito. Es decir, el trabajo que él despliegue frente al gobernante o autoridad competente debe tener eficacia, resultados, ser convertido en beneficios para la comunidad afectada por las situaciones indeseadas o valoradas como negativas.

Cada situación problemática de la comunidad tiene diferentes características que permiten adecuarlas y agruparlas según sea la situación en sí misma y del interés personal del líder comunitario convertido en empresario político. Cobb y Elder (1993) recuerdan que estos objetivos revisten al menos cuatro tipos diferentes, y que cada uno de ellos induce un proceso de acción particular.

El líder comunitario debe aprehender instrumentos cognitivos que lo lleven a adquirir hábitos en forma tal que le sea fácil identificar las oportunidades de convertirse en empresario 
político, difícilmente lo hará solo, es labor de las autoridades públicas nacionales y territoriales crear instituciones de formación permanente que le brinden esta oportunidad a ellos bajo la concepción de crear una malla de ciudadanos educados políticamente, con clara conciencia de una dialéctica de concertación humana.

Luego de asumir la problemática social como suya el siguiente paso que debe hacer el líder comunitario, como empresario político, es lanzar un desafío a la autoridad pública; si el desafío es asumido, el problema pasa a ser sujeto de debate público, por lo que su inclusión en la agenda es muy probable.

\section{c) La agenda}

Existe una condición estructural en el modelo propuesto; para que un problema social se convierta en problema público, éste debe convertirse en parte de la agenda institucional del gobernante.

La agenda es una construcción política dependiente de variables de todo tipo involucradas en la distribución de poder en una institución pública en un momento y lugar determinado. Para Cobb y Elder (1993) por formación de la agenda se entiende el proceso a través del cual ciertos problemas sociales llegan a llamar la atención, voluntaria u obligada por las circunstancias, del gobierno como posibles asuntos de política pública.

Meny y Thoenig (1992) definen la agenda, como un conjunto de problemáticas sociales objeto de controversias públicas, entre los intereses de actores políticos y los gobernantes, sobre las que se exige la intervención de las autoridades públicas competentes. Lo anterior significa que todos los problemas sociales no se hallan contenidos al mismo tiempo en la agenda del gobernante, algunos figuran y otros no. Es, pues, un mecanismo selectivo que deja pasar o no, tal o cual problemática. Lo que los políticos llaman inscribir en la agenda, es un mecanismo esencial en una sociedad política, que desarrollado bajo dinámicas democráticas debe disminuir el peligro de nacimiento de confrontación de otro tipo, como las armadas. El líder comunitario debe entender claramente esto, y en el momento que decide asumir su papel como empresario político con respecto a un asunto o inconformismo social, su objetivo será lograr que este penetre la agenda. Al Estado le compete la responsabilidad de crear las condiciones administrativas y políticas para que este fenómeno se pueda realizar en condiciones legales y legítimas.

Una de las competencias en las que un líder comunitario, convertido en empresario político, debe tener más formación es en la definición de problemas, ya que esto le permitirá ser eficaz en su accionar, poder vislumbrar con anterioridad qué situación indeseada, por la comunidad o parte de ella, puede tener mayor probabilidades de éxito al momento de querer convertirla en problema público. La definición correcta de un problema es clave para su tratamiento posterior por parte de la autoridad pública competente. El mal diagnóstico de una problemática traerá 
como consecuencia un mal tratamiento; es posible que las acciones desarrolladas frente al mismo tengan efectos nocivos y no paliativos o curativos, ocasionando la agudización de la crisis, incluso el surgimiento de nuevas realidades indeseadas. El Estado a través de sus autoridades públicas ahorraría muchos recursos financieros, políticos, humanos, si implementará políticas públicas para la formación de los líderes comunitarios en esta área del conocimiento.

Según Cobb y Elder (1993) el punto fundamental no consiste en que el acceso a la agenda gubernamental suceda por azar, sino que debe ser el producto de un complejo proceso que frecuentemente posee una estructura informal y laxa. Las decisiones de una autoridad pública se presentan como el resultado de cuatro variables interdependientes: las personas, los problemas, las soluciones y las oportunidades de elección.

El Estado debe desarrollar políticas públicas cuyo objetivo fundamental sea la formación de los líderes comunitarios como transformadores de problemas sociales en problemas públicos, como mecanismo de participación ciudadana para fortalecer la democracia participativa. Mediante estas acciones de formación el líder comunitario aprenderá a que existen mecanismos de derecho y jurídicos a los que puede recurrir dentro de la legalidad y la legitimidad. El blanco, del líder, es la agenda de la autoridad pública, su misión penetrarla, su propósito conseguir que el gobernante actúe frente al problema social.

\section{d) El gobernante o autoridad pública}

El que decide y define como utilizar los recursos a su disposición. El gobernante o la autoridad pública es, también, un empresario político, por lo que sus intereses van a primar en el desarrollo de la agenda. Puede actuar presionado por diferentes actores, aliados o extraños, que buscan penetrar la agenda para que sus intereses adquieran prioridad y se tomen acciones inmediatas o se implementen políticas públicas frente a los mismos; o lo puede hacer de forma proactiva, anticipándose a cualquier acción diferente a sus propios intereses.

El líder comunitario lanza un desafío a la autoridad pública y ésta, según su criterio o capacidad de reacción, decide aceptarlo o no. En el primer caso, decimos que se le está permitiendo acceso a la agenda y por lo tanto el problema social es convertido en problema público; en el segundo caso, el problema social continuará como una necesidad o descontento de la comunidad hasta que se den nuevamente condiciones para que el gobernante evalúe su importancia o que el líder comunitario que lo lidere, realice las estrategias necesarias para que vulnere la agenda.

Son múltiples las razones para que un problema social se convierta en desafío y logre entrar en la agenda. Algunas de éstas son propuestas por Meny y Thoenig (1992) así: A) Que el problema social consiga notoriedad en los públicos, actores o público en general, hasta el punto de presionar un debate, a la autoridad pública, respecto del mismo. B) Que el problema social esté conectado con tendencias, valores o asuntos que estén de moda. C) Que el problema 
social sea provocado en una situación emotiva que exacerba el deseo de rating de los medios de comunicación. y D) Que el problema social alcance proporciones de crisis haciendo difícil que se ignore su existencia.

Frente a los problemas sociales que son abanderados por los líderes comunitarios, el gobernante o la autoridad pública, tienen elecciones para responder y decidir si decide o no incluir en la agenda el desafío, es decir, convertirlos en problemas públicos; Meny y Tohenig (1992) proponen algunas de estas opciones como:

a) Estrategias de rechazo al desafío lanzado por el líder comunitario convertido en empresario político. Los problemas sociales no entran a la agenda y por lo tanto no se convierten problemas públicos. Por ejemplo, rechazar de plano el desafío y decidir de inmediato que ese problema social no hace ni hará parte de su agenda, implementar tácticas de corrupción frente a los empresarios políticos que hayan asumido determinado problema social, actuar sobre el problema él mismo, desactivándolo, bloqueándolo, tomándolo a bromas, o lo que es más usado últimamente, aludiendo que son prácticas de la oposición política. También es posible que mediante estrategias comunicacionales, desacredite a los líderes; finalmente, puede crear o ampliar rivalidades entre los diferentes grupos de presión que tengan intereses en la problemática social. El líder comunitario debe ser un ciudadano dotado de una moral y una ética propia sólida, con una autoestima fuerte, por lo que el Estado puede crear procesos de construcción sicológica de valores.

b) Estrategias de atención favorables, según grados distintos pero moduladas tácticamente. Los problemas sociales entran en la agenda y por lo tanto se convierten en problemas públicos. Ejemplos: enviar señales simbólicas que muestren que le interesa la problemática, pero, sólo buscando ganar tiempo para que el problema se diluya en el tiempo. Invocar imponderables, es decir, razones poderosas, de fuerza mayor, por encima de sus competencias o recursos pero que no le permiten actuar frente a la problemática social que pretende ser convertida en problema público. Crear, prometer o implementar, organismos que le ayuden a postergar el examen del problema, por ejemplo, la creación de comisiones de expertos es un medio clásico para demorar el enfrentamiento de la problemática social. Muchos ciudadanos opinan que la mayoría de los problemas sociales se solucionan con la creación de burocracia, y también los gobernantes que quieren cumplir con sus compromisos politiqueros, ven ciertas situaciones como oportunidades de crear cargos públicos.

Establecer nuevos procedimientos para el tratamiento del problema, pero sin compromiso real en cuanto al contenido. La puesta en marcha de un servicio especializado al que se confía la definición de procedimientos específicos, frente a la situación incómoda, constituye una ilustración de lo anterior. Producir nuevas reglamentaciones sobre una parte del problema, como una acción emblemática, pero sin abordar efectivamente las soluciones 


\begin{tabular}{cc}
\hline & ANTONIO YESID PEDROZA ESTRADA \\
$>140$ & LOS PROBLEMAS PÚBLICOS COMO FACTOR ESTRUCTURAL DE LAS POLÍTICAS PÚBLICAS \\
Págs. $123-143$. DOI: $h t t p: / / d x . d o i . o r g / 10.30972 / r f c e .0203258$
\end{tabular}

efectivas respecto del conflicto. Una muestra es la de ofrecer un subsidio de empleo para los desempleados, pero no crear condiciones para que se formalicen nuevas empresas. Actuar proactivamente y anticiparse con acciones y políticas públicas al surgimiento de nuevas situaciones indeseadas, ganándose los réditos políticos en vez de esperar las actuaciones de otros empresarios políticos. Un gobernante no tiene los recursos necesarios para solucionar todos los problemas sociales, entre otras cosas, porque estos son infinitos, pero la eficacia se busca en todas sus actuaciones, no se trata de gastar bien los recursos, si no de solucionar los problemas de fondo. Si esto llega a ser percibido por el líder comunitario, este debe dejar de lado su propio interés y colocar la comunidad como el fin último de las acciones y políticas públicas de las autoridades públicas; convertirse en un aliado puede dejar mucho provecho.

\section{e) La sociedad civil y los problemas públicos}

El concepto de sociedad civil es motivo de múltiples significados dependiendo del tiempo y el espacio. Para Locke (1689), por ejemplo, la sociedad civil, es formada en el momento en que un número cualquiera de hombres se juntan y abandonan cada uno su ley de la naturaleza y se somete a un poder superior denominado poder público. El hombre, en comunidad, decide someterse a un poder legislativo y sus leyes, asumiendo unos deberes y reclamando unos derechos.

Para el Banco Mundial (BM, 2016) en cambio, la sociedad civil está compuesta por organizaciones no gubernamentales, grupos basados en su fe común, sindicatos, poblaciones indígenas y originarias, organizaciones de caridad, agrupaciones locales y fundaciones privadas, las cuales sean constituido en una potencia importante en el desarrollo internacional en los últimos veinte años, ayudando a tener mayor gobernabilidad en los Estados democráticos del mundo. Según el BM (2016) en las dos últimas décadas la Sociedad civil ha sido indispensable en campañas mundiales como las dedicadas a conseguir la prohibición de las minas terrestres o la protección ambiental que han movilizado a miles de simpatizantes en todo el mundo.

El BM (2016) cree que las campañas entre la sociedad civil, el gobierno y el sector privado son la forma más efectiva para que se logre el crecimiento económico y el desarrollo sostenible en nuestras democracias modernas, citando variados beneficios entre los que se encuentran: mayor participación de las partes interesadas, promoción de la responsabilidad y transparencia del sector público al ejercer mayores presiones para una buena gobernabilidad; desarrollo de ideas y soluciones innovadoras, como también una mayor participación local en la búsqueda de soluciones a los problemas locales, y entrega de competencia profesional y mayor capacidad de prestación de servicios, especialmente en los casos en que el sector público no tiene capacidad suficiente para proporcionar servicios o en situaciones posteriores a un conflicto. 


\section{CONCLUSIONES}

Finalmente, se sostiene que el líder comunitario es un elemento estructural de las agrupaciones locales o comunitarias en los países con gobiernos democráticos, y por lo tanto es definitivo para construir las condiciones políticas adecuadas para que las problemáticas sociales entren a la agenda gubernamental, transformando las mismas en problemas públicos, que tengan como consecuencia acciones de gobierno o políticas públicas que mejoren la calidad de vida de la comunidad en general.

El Estado debe recapacitar sobre el papel del líder comunitario y verlo como un aliado para enfrentar los problemas de gobierno y los sociales en general. Se debe pensar en políticas públicas que faciliten el protagonismo del líder comunitario como elemento catalizador y dinamizador de las acciones públicas para enfrentar los problemas sociales.

Los movimientos sociales de las últimas décadas han demostrado cómo la sociedad civil organizada ha generado cambios en países que gozaban de gobernantes cuyo mayor poder residía en sus políticas represivas, a pesar de que en algunos de ellos tenían buenos niveles en su calidad de vida, pero que carecían de bienes esenciales, propios de las democracias, como la posibilidad de tener libertad de expresión, religión, educación, etc. En general en Latino América, especialmente en Colombia, es indudable que debe existir un cambio estructural en la forma de distribución del poder, la ciudadanía lo reclama, y es menester de los gobiernos crear las condiciones jurídico-políticas para que el ciudadano, y su representante: el líder comunitario, sea un protagonista más visible de las nuevas realidades sociales, propiciando los espacios de participación, control ciudadano y confrontación política al mismo tiempo que se restan limites a los escenarios de la dialéctica de la confrontación armada.

\section{REFERENCIAS BIBLIOGRÁFICAS}

Aguilar, L. F. (Ed.). (1993). Problemas públicos y agenda de gobierno. México D.F., México. Editorial Miguel Ángel Porrúa.

Banco Mundial. (2016). Reseña sobre la sociedad civil. Washington, E.U. Recuperado de http://www.bancomundial.org

Briones, G. (2003). Métodos y técnicas de investigación para las ciencias sociales. Editorial trillas. Bogotá, Colombia. 


\begin{tabular}{c}
\hline ANTONIO YESID PEDROZA ESTRADA \\
$>142$ LOS PROBLEMAS PÚBLICOS COMO FACTOR ESTRUCTURAL DE LAS POLÍTICAS PÚBLICAS \\
Págs. $123-143$. DOI: $h t t p: / / d x$. doi.org $/ 10.30972 / r f c e .0203258$
\end{tabular}

Cobb, R. y Elder; C. (1993). Formación de la agenda. El caso de la política de los ancianos. En L. F. Aguilar (Ed.), Problemas públicos y agenda de gobierno. (pp. 77-104). México D.F., México. Editorial Miguel Ángel Porrúa.

Fukuyama, F., Botana, N., Curvale, C., Dominguez, J.,Gonzalez, F., Halperin D., T.,...Roet, R. (2006). La brecha entre América Latina y Estados Unidos. Determinates políticos e instituciones del desarrollo económico. Buenos Aires, Argentina. Fondo de cultura económica.

Hernández, R. y otros. (2016). Metodología de la investigación. Editorial Mc Graw Hill. México D.F. México.

Locke, J. (1689). Segundo tratado sobre el gobierno civil. Recuperado de: https://dairoorozco. files.wordpress.com/2013/o1/locke-segundo-tratado-sobre-el-gobierno-civil.pdf

Maslow, A. H. (2005). El management según Maslow: una visión humanista para la empresa de hoy. Barcelona, España. Editorial Paidós Ibérica.

Meny, I. y Thoenig, J. (1992), Las políticas públicas. Barcelona, España. Editorial Ariel.

Rodríguez, G.; Gil, J. y García, E. (2011) Metodología de la investigación cualitativa. España: Algive.

Roth, A. (2013). Políticas públicas. Formulación, implementación y evaluación. Bogotá, Colombia. Ediciones Aurora.

Ruiz, D., Cadena, C. (s.f.). Qué es una política pública. Revista IUS. Universidad Latina de Americana. Recuperado de: http://www.unla.mx/iusunla18/reflexion/QUE\%20ES\%20 UNA\%2OPOLITICA\%2oPUBLICA\%2oweb.htm

Soros, G. (2002). Globalización (p.40). Barcelona, España. Editorial planeta.

\section{COMO CITAR ESTE ARTÍCULO:}

PEDROZA ESTRADA, Antonio Yesid. Los problemas públicos como factor estructural de las políticas públicas. Revista de la Facultad de Ciencias Económicas - UNNE. Número 20, otoño 2018, ISSN 1668 - 6365. Págs. 123 - 143. DOI: http://dx.doi.org/10.30972/rfce.0203258 


\section{CURRICULUM VITAE}

\section{Antonio Yesid Pedroza Estrada}

Doctor en Ciencias Políticas. Abogado. Administrador de Empresas. Especialista en Gestión Pública. Docente investigador de la Universidad Popular del Cesar y de la Escuela Superior de Administración Pública, ESAP, Colombia.

yesithpedroza@hotmail.com 